\title{
ON STRAIN RATE SENSITIVITY OF BETA-TITANIUM ALLOYS
}

\author{
A. KOBAYASHI, N. TAKEDA, S. OGIHARA and Y.C. II \\ Department of Materials Science, Faculty of Engineering, The \\ University of Tokyo, Hongo 7-3-1, Bunkyo-ku, Tokyo 113, Japan
}

\begin{abstract}
Résumé : Des alliages de béta-titane de type $\mathrm{Ti}-15 \mathrm{~V}-3 \mathrm{Cr}-3 \mathrm{Al}-3 \mathrm{Sn}$ sont testés en traction à une vitesse de déformation de $10^{3} \mathrm{~s}^{-1}$ par la méthode à une barre afin de mesurer la sensibilité de cet alliage à la vitesse de déformation. On montre que la contrainte ultime, la déformation maximale associée et l'énergie absorbée augmentent avec la vitesse de déformation. Les courbes contrainte-déformation en dynamique sont également obtenues.
\end{abstract}

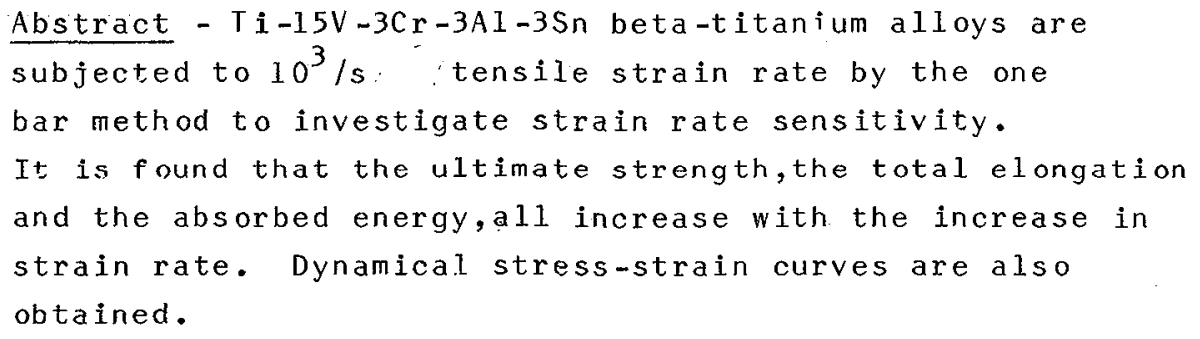

\section{Introduction}

Titanium alloys are useful especialiy in the/aircraft structures as is well known. Recently, the industry is requiring more superior titanium alloys, among which a beta-titanjum alloy is noteworthy. In this respect,strain rate sensitivity is investigated in the present paper, i.e.,high strain rate tension is applied to such beta $T i$ alloys in comparison with the quasi-static case.

\section{Preparation of Specimen}

Beta Ti alloys used in the present study is hot-roiled,solutiontreated and aged. The chemical composition,processing conditions and the static mechanical properties at room temperature are shown in Table 1 . 
In Table 1,PS is a proof stress with $0.2 \%$ permanent set,TS a tensile strength,EI an elongation, RA the reduction in area and COD crack opening displacement.

Table 1. Specimen characteristics/processing

Chemical Composition (mass\%)

\begin{tabular}{cccccccccc}
\hline $\mathrm{V}$ & $\mathrm{Cr}$ & $\mathrm{Sn}$ & $\mathrm{Al}$ & $\mathrm{O}$ & $\mathrm{N}$ & $\mathrm{C}$ & $\mathrm{Fe}$ & $\mathrm{H}$ & $\mathrm{Ti}$ \\
\hline 14.9 & 3.26 & 3.38 & 3.28 & 0.082 & 0.011 & 0.006 & 0.04 & 0.008 & $\mathrm{bal}$. \\
\hline
\end{tabular}

Processing Conditions

$\frac{\begin{array}{l}\text { Vacuum Arc } \\ \text { Melting }\end{array}}{\begin{array}{c}1000 \mathrm{~kg} \\ 500 \mathrm{~mm} \text { dia. }\end{array}} \rightarrow \underset{\text { beta field }}{\text { Hot Forging }} \rightarrow \underset{\substack{1050^{\circ} \mathrm{C} \\ t=13 \mathrm{~mm}}}{- \text { Hot Rolling }} \rightarrow \frac{\text { STOA }}{\text { Heat Treatment }}$

Solution Treatment (ST): $800^{\circ} \mathrm{C} \times 20 \mathrm{~min}$ Water Quenching Aging (OA): $\quad 500^{\circ} \mathrm{C} \times 100 \mathrm{~h}$ Air Cooling

Static Mechanical Properties at Room Temperature $0.2 \% \mathrm{PS}(\mathrm{GPa})$ TS (GPa) El (\%) RA (\%) Critical COD (mm)

$\begin{array}{lllll}1.15 & 1.22 & 11 & 22 & 0.027\end{array}$

Specimen dimension is shown in Fig.l

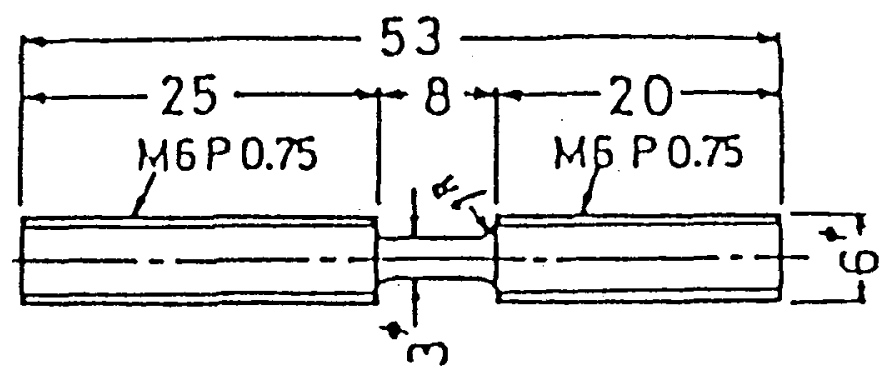

Fig.l Specimen dimensions(Unit:mm) 


\section{Loading and Measuring Systems}

For loading system, so-called the one bar method is employed./1/

The very method was developed by Dr.Kawata,now professor emeritus of The University of Tokyo, and his research group to obtain precise dynakical stress-strain curves. As shown in Fig.2, the system consists of an impact block, a specimen, a hammer and an output bar. Briefly, the impact block is subjected to impact by a hammer attached to a rotating disk when the disk reaches the prescribed desired speed. Then a generated stress wave in the specimen propagates into the output bar. Now the strain produced in this output bar is measured by a measuring system as follows.

The very strain $\mathcal{E}_{g}(t)$ is measured by semiconductor strain gages (4 gages circumferentially) at a distance a from the impact end of the output bar,before the reflected stress wave reaches these strain gages. The impact block velocity $V(t)$ is measured through electrooptically. Thus the stress and strain in the specimen are calculated by the one-dimensional stress wave theory as follows;

$$
\sigma(t)=\left(s_{0} / s\right) E_{0} \varepsilon_{g}(t+a / c), \quad \varepsilon(t)=(1 / L) \int_{0}^{t}\left[v(\tau)-c \varepsilon_{g}(\tau)\right] d \tau
$$

where $L$ and $S$ are length and sectional area of the specimen, and $S_{0}, E_{0}$ and $c$ are sectional area, $Y$ oung's modulus and elastic wave velocity of the output bar. The measuring system is shown in Fig.2.

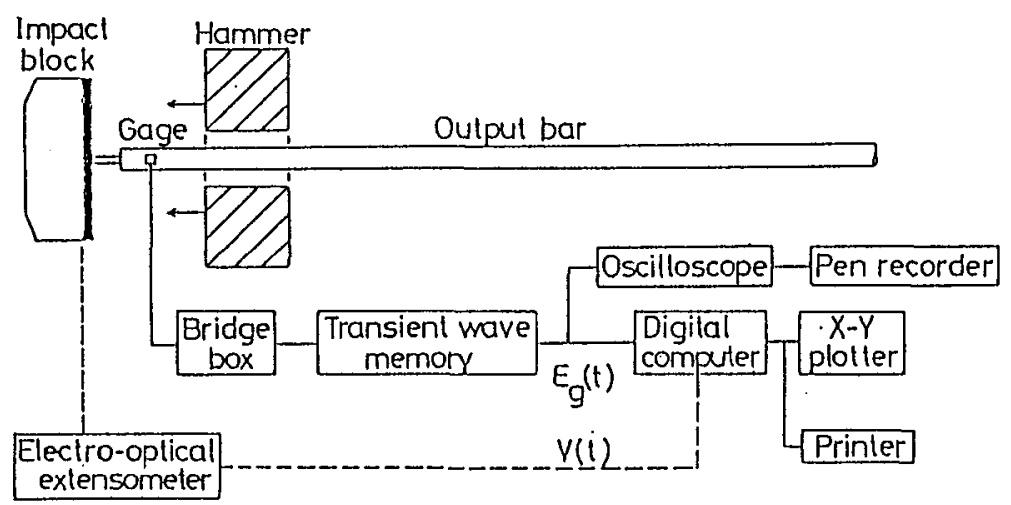

Fig.2 Loading and measuring systems 
4.Experimental Results

Stress-strain curves for the quasi-static cases of strain rate $10^{-3} / \mathrm{s}$ and for the dynamical ones of $10^{3} / \mathrm{s}$ are shown in Figs. 3 and 4.

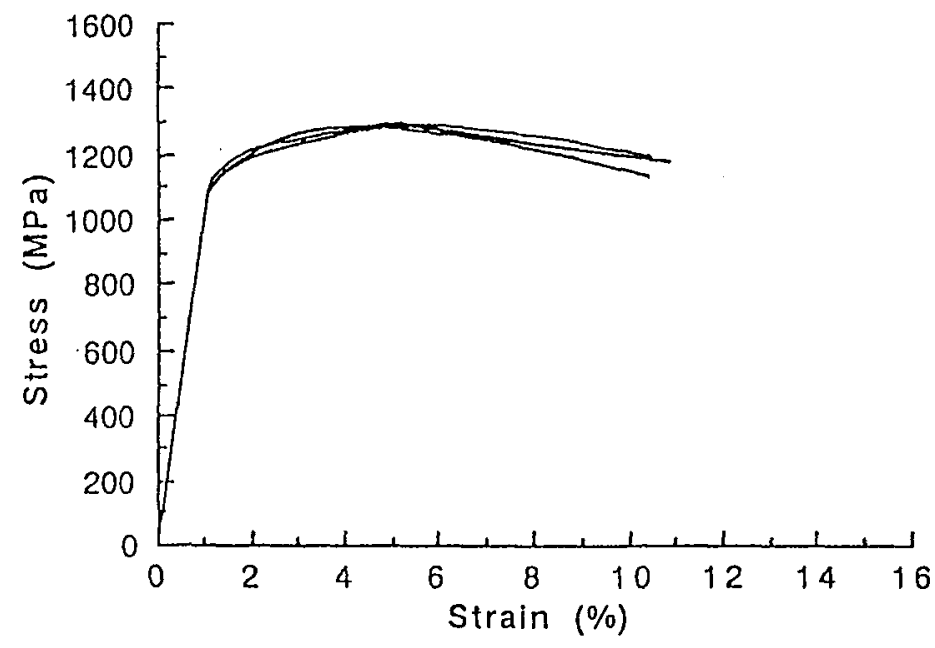

Fig. 3 Quasi-static cases

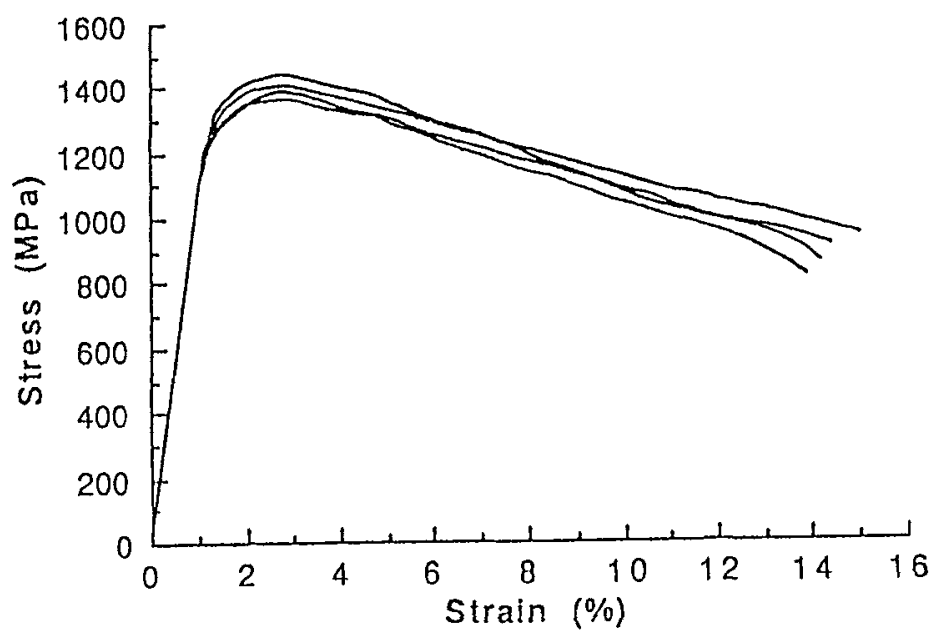

Fig.4 Dynamical cases 
In order to investigate the strain rate sensitivity of this beta titanium alloys,three characteristic values, i.e.,ultimate strength, total elongation and absorbed energy are compared with those in the quasi-static cases, as shown in Figs. 5 to 7 .

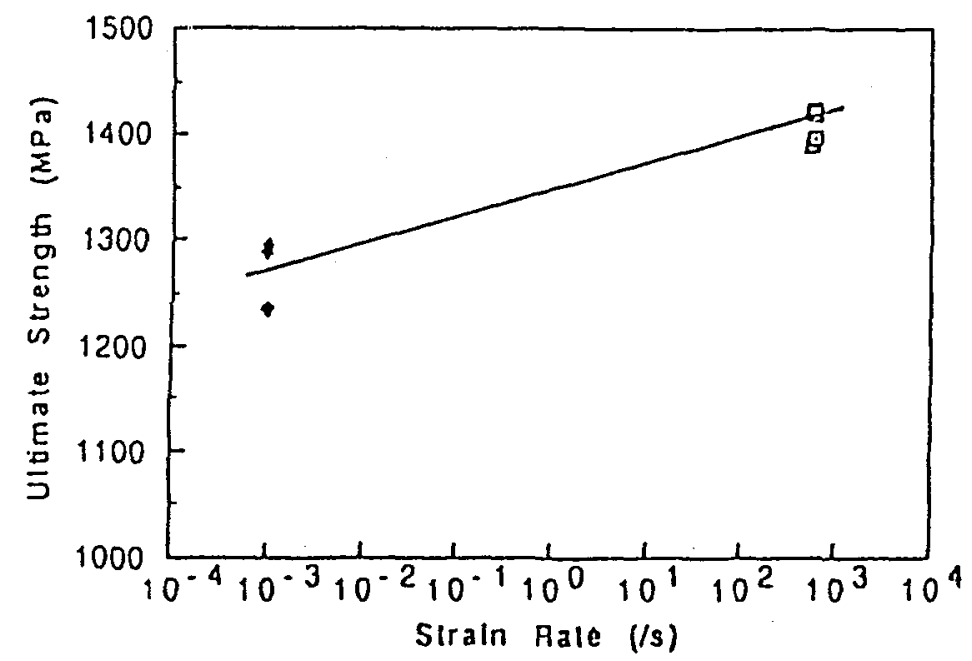

Fig. 5 Ultimate strength vs.strain rate

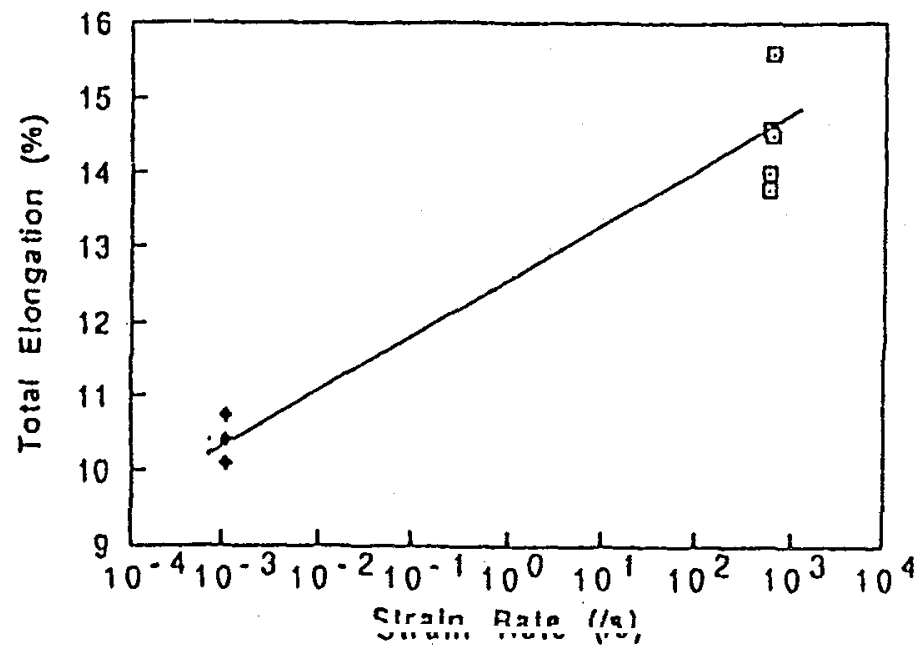

Fig.6 Total elongation vs. strain rate 


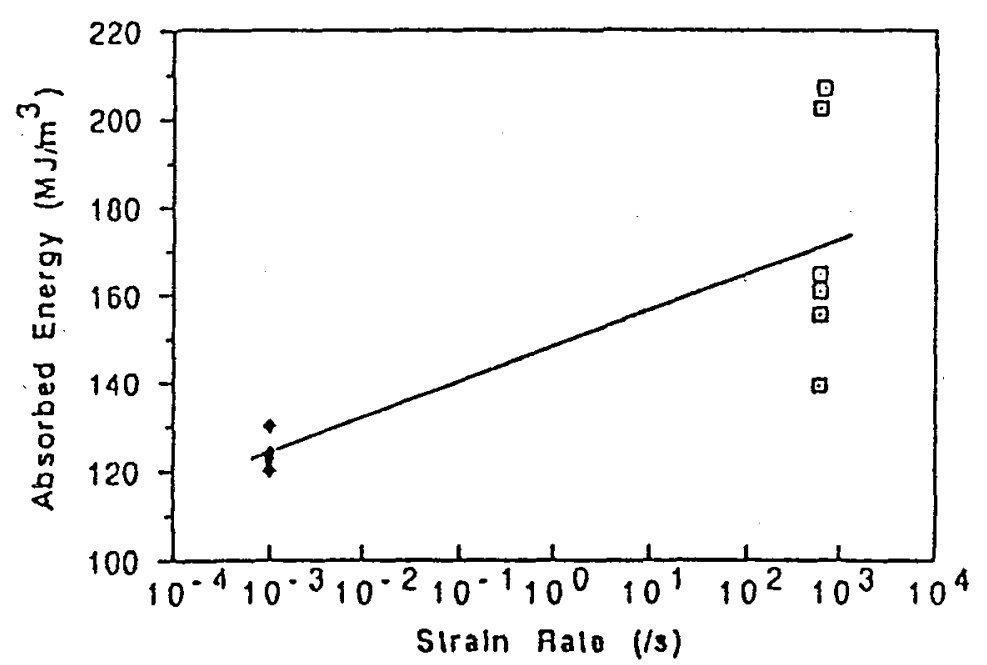

Fig.7 Absorbed energy vs. strain rate

As shown in Figs.5 to 7 ,all the characteristic values increase with the increase in strain rate. These increasing ratios are roughly estimated as 1.1 for ultimate strength, $1.4 \mathrm{f}$ or total ediongation and also 1.4 for absorbed energy. Thus the beta-titanium alloys give much strain rate sensitivity so far as the present test results are concerned. This means the beta-titanium alloys offer very desirable properties in high strain rate tension loading.

Rosenberg found the beta-titanium alloys in the annealed condition were insensitive to the quasi-static strain rates ranging from $10^{-4} / \mathrm{s}$ to $2 \times 10^{-3} / \mathrm{s} / 2 /$. No available data in the dynamical case are presented for this beta-titanium alloys except for the present study.

Acknowledgements

Nippon Steel' Corporation is appreciated for offering specimens.

\section{References}

1. Kozo Kawata, Shozo Hashimoto et al., Mechanical Properties at High Rates of Strain, Inst. Phys., Lond on (1979)71.

2. H.W.Rosenberg, Beta Titanium Alloys in the 80's, AIME, New York, (1983)409. 